\title{
Effects of small-scale management on biodiversity of an abandoned coppice forest in Japan: a case study on vegetation regeneration and ground beetle community
}

\author{
Sonomi Shibuya, Kôhei Kubota and Masahiko Ohsawa
}

\begin{abstract}
Shibuya, S., Kubota, K. and Ohsawa, M. 2008. Effects of small-scale management on biodiversity of an abandoned coppice forest in Japan: a case study on vegetation regeneration and ground beetle community. - Web Ecol. 8: 116-124.
\end{abstract}

\begin{abstract}
We studied the effects of small-scale vegetation disturbances on biodiversity in an abandoned coppice forest in central Japan during 2004-2006. We assessed biodiversity by examining vegetation regeneration and by changes in the diversity and abundance of ground beetles after experimental manipulations including tree felling, vegetation clearing, and litter removal. Our experimental design was dictated by the need of producing only small disturbances; therefore we could not replicate plots. Instead, we used a repeated measures approach during three years to document the consistency of experimental effects. We found that the diversity of regenerating vegetation increased dramatically due to recruitment of many new species after clearing ground vegetation. Tree cutting caused strong environmental changes and affected vegetation regeneration rate but not diversity. Tree cutting also significantly increased the diversity of ground beetle species, while litter removal affected the abundance of ground beetles. Our results suggest that a sound conservation practice shall combine tree cutting with ground vegetation clearing and litter removal. Besides, conservation of abandoned forests may be based on low-intensity labor, including tree cutting on restricted areas. Finally, ground beetles appeared to be surprisingly sensitive to vegetation disturbance on a restricted area and thus can be suggested for monitoring such small-scale-disturbance-based conservation practices.
\end{abstract}

S. Shibuya (sshibuya@nenv.k.u-tokyo.ac.jp), Laboratory of Biosphere Functions, Graduate School of Frontier Sciences, The University of Tokyo, Kashiwa, JP-277-8653 Chiba, Japan. - K. Kubota, Laboratory of Forest Zoology, Graduate School of Agricultural and Life Sciences, The University of Tokyo, Bunkyo-ku, JP-113-8657 Tokyo, Japan. - M. Ohsawa, Laboratory of Biosphere Functions, Graduate School of Frontier Sciences, The University of Tokyo, Kashiwa, JP-277-8653 Chiba, Japan.

Coppice forests were once common in Japan. These forests were cut for firewood and charcoal with 10 to 25 years of rotation, and ground vegetation was cleared and litter was collected for compost usually once a year (Moriyama 1988, Takeuchi 2003). Traditional management maintained forests with large pools of plant species (Iida and Nakashizuka
1995, Fukamachi et al. 2001), which coexisted sustainably with unmanaged ones (Brown and Yokohari 2003). However, the introduction of fossil fuels and chemical fertilizers in the 1960s as well as changing lifestyles in Japan led to dramatic decline in traditional use of forests, which eventually were largely abandoned (Okubo et al.

Accepted 20 August 2008

Copyright (C) EEF

ISSN 1399-1183 
2005) reducing biodiversity in coppice forests (Brown and Yokohari 2003) particularly for birds (Ichinose and Katoh 1998) and lepidopterans (Inoue 2003, Nishinaka and Ishii 2007, Ohwaki et al. 2007). Conservation of the coppice forests is problematic because the old management regime was labor-intensive, which today is not cost-effective. The attempts of management of coppice forests today are often reduced to clearing ground vegetation, which is believed to be enough for maintaining most biodiversity in abandoned forests. While it is important to conserve biodiversity of traditionally managed forests (Hiroki 2002, Ishii 2005), little is known about the effectiveness of management practices used today. We need new, more practicable and efficient ways of conservation. Because the traditional management is not feasible today, we need to know whether conservation can be based on small-scale, cost-effective interventions.

The general aim of our study was to examine the effects of small-scale vegetation disturbance on the biodiversity of an abandoned coppice forest. For this purpose we experimented with different types of vegetation disturbance within a limited area, and examined the effects of these disturbances on two different components of biodiversity: vegetation and ground beetles. Vegetation is the principal component of the forest, and plants are easy to manipulate and monitor. However, vegetation processes are slow, and for our short-term study we could only focus on the regeneration processes: growth rate and recruitment of new species. We studied these processes for three years of the experiment and analyzed the obtained data for assessing the effects of vegetation disturbance on plant diversity in the coppice forest. Another component, convenient for monitoring biodiversity within a limited space, are ground beetles.

The Carabidae is a particularly popular group of ground beetles for their sensitivity to environmental changes (Thiele 1977, Niemelä et al. 1993, Ishitani 1996, Ishitani et al. 2003). Many studies conducted in Europe and North America has demonstrated the potential of carabid beetles as bioindicators (Irmler 2003, Rainio and Niemelä 2003, Scott and Anderson 2003, Niemelä et al. 2007). In forests of central Japan, however, the most common ground beetle is the silphid Eusilpha japonica (Shimada 1985, Shimada et al. 1991, Taniwaki et al. 2005). Unlike other Silphidae species, E. japonica is not a carrion beetle but a flightless predator, like the Carabidae (Ikeda et al. 2007). Eusilpha japonica has good potential as a bioindicator (Shibuya et al. 2008), and we included it in our analyses as a representative of ground beetles.

Our study was restricted within a compact, homogenous area because the main purpose was to assess the effects of small-scale vegetation manipulations based on the limited use of manpower. This restriction made it difficult to use an experimental design with replicated plots. To solve the problem of replications, we used repeated measures ANOVA based on recurring measurements over three years of the study. Other statistical analyses we performed for each year separately; if the effects were observed consistently for these years we considered them robust and significant.

\section{Material and methods}

\section{Site description and experimental design}

Our study was carried out in Musashi-Kyûryô National Park in Namekawa-cho, Saitama Prefecture, central Japan $\left(36^{\circ} 04^{\prime} \mathrm{N}, 139^{\circ} 22^{\prime} \mathrm{E}, 40\right.$ to $90 \mathrm{~m}$ a.s.l.). The study site is located in a humid warm-temperate part of Japan, with a maximum summer temperature of $33^{\circ} \mathrm{C}$ in August, a minimum winter temperature of $-3^{\circ} \mathrm{C}$ in January, and a mean annual temperature of $14.8^{\circ} \mathrm{C}$; precipitation averages $1479 \mathrm{~mm}$ per year (meteorological data measured on the park territory during 2004-2006). The park covers 304 ha and consists of 'abandoned' patches where no management takes place, and patches that are occasionally subjected to ground vegetation clearing and litter removal. Tree felling stopped when the park was established in 1974. We selected a large patch of abandoned coppice forest $(80$ $\times 100 \mathrm{~m})$ in the center of this park. This patch was located on a mild slope (inclination of five degrees) facing east and could be considered topographically homogeneous.

We documented the original conditions in this forest patch by conducting a preliminary study that included sampling of the ground vegetation (10 randomly placed $1 \times 1 \mathrm{~m}$ quadrats) and a tree inventory. This preliminary survey revealed that dwarf bamboo Pleioblastus chino dominated the ground vegetation $(90 \%$ of the vegetation cover), with a mean density of 41 culms $\mathrm{m}^{-2}$ and maximum and mean heights of 4.2 and $2.7 \mathrm{~m}$, respectively. Quercus serrata dominated the tree canopy of the site. The annual rings at a height of $10 \mathrm{~cm}$ of the trees cut during the experiment (below) showed a maximum age of 43 years. Consequently, the forest was last cut more than 40 years ago, and during the four decades of abandonment, Q. serrata and dwarf bamboo had become the dominant species in the canopy and ground layers, respectively.

The experimental manipulations of vegetation included tree cutting, ground vegetation clearing and litter removal. These three types of vegetation disturbance essentially represent the traditional management of a coppice forest in Japan. We laid out an experimental site $(40 \times 20 \mathrm{~m})$ in March 2004 and divided it into four adjacent $10 \times 20 \mathrm{~m}$ plots. This plot size was selected because the disturbance should be applied to a small, compact area that requires a minimum use of manpower. We tested the following three types of experimental manipulations and their combinations (Table 1):

1) Tree cutting: all trees (woody vegetation $>1.3 \mathrm{~m}$ tall) were cut at $10 \mathrm{~cm}$ above the ground and removed from 
Table 1. Design for experimental vegetation disturbances.

\section{Manipulations on vegetation}

Plot Ground vegetation clearing Tree cutting Litter removal

\begin{tabular}{lccc}
\hline P1 & cleared & cut & removed \\
P2 & cleared & cut & not removed \\
P3 & cleared & uncut & removed \\
P4 & cleared & uncut & not removed \\
P5 & not cleared & uncut & not removed \\
\hline
\end{tabular}

the plot in March 2004 in two plots (P1 and P2). Overall we cut 82 tree individuals, among them Q. serrata (36 individuals), Rhododendron kaempferi (22), Eurya japonica (12), Ilex macropoda (8), Styrax japonica (2), Lyonia ovalifolia (1), and Viburnum dilatatum (1).

2) Ground vegetation clearing: dwarf bamboo, small trees $(<1.3 \mathrm{~m}$ tall), and herbs were cut and removed from the all four plots in March 2004 and in March 2006.

3) Litter was removed in P1 and P3 in March 2004, and again in March 2006.

The plots are located lining up in order of P1, P2, P3 and P4 (from south to north) on the manipulation site. We set up one $10 \times 20 \mathrm{~m}$ control plot (P5) located $5 \mathrm{~m}$ west from the manipulation site.

\section{Environmental variables}

We measured 20 environmental variables grouped in four categories, which described canopy trees, ground vegetation, litter and soil (Table 2).

For the tree variables, we identified the species and measured height and diameters at breast height $(\mathrm{DBH}$, $1.3 \mathrm{~m}$ above ground) of all individuals taller than $1.3 \mathrm{~m}$ within the plots in February and March 2004. We used these results as the representative tree variables in 2004, 2005 and 2006. For each species, we calculated the basal area (BA) and relative basal area (RBA, \% of total BA for a species) from the $\mathrm{DBH}$ data. We also measured the canopy openness from hemispherical photos taken $50 \mathrm{~cm}$ above the ground at four different points within each plot in September 2004, 2005 and 2006, and we calculated the mean openness (\%) by using CanopOn 2.02 software (Takenaka 2007).

For the ground vegetation, we sampled all herbs and trees shorter than $1.3 \mathrm{~m}$. We recorded the maximum height and total coverage (\%) of each species within the plots in August and October 2004, August and September 2005 and June and November 2006. Projective coverage (\%) of ground vegetation was monitored each month in each plot from January 2004 to November 2006. The aboveground biomass of a given species was measured as a 'volume', which is the maximum height of the species mul- tiplied by its total projective coverage. Then these results were used to calculate the following diversity indices: (a) overall richness (number of species), (b) Pielou's evenness: $\left(-\sum \mathrm{p}_{\mathrm{i}} \times \log _{2} \mathrm{p}_{\mathrm{i}} / \log _{2} \mathrm{~S}\right.$, where $\mathrm{p}_{\mathrm{i}}$ is the proportion of aboveground biomass accounted for by the ith species, and $S$ is the number of species; Pielou 1975), (c) Simpson's diversity index: $\left(1-\sum \mathrm{p}_{\mathrm{i}}^{2}\right.$, Magurran 1988).

In addition, the annual maximum coverage and biomass of all ground vegetation, and the biomass and maximum height of dwarf bamboo were measured.

We used dry weight of litter as its descriptor variable. We collected litter samples from four small quadrats $(0.3 \times$ $0.3 \mathrm{~m}$ ) within each plot in February, March and September 2004, March 2005 and March and December 2006 to see the variation during the season. We oven-dried the samples at $80^{\circ} \mathrm{C}$ for $48 \mathrm{~h}$ and then weighed the samples to calculate mean values for each sampled plot. We used the March results in 2004, 2005 and 2006 in our subsequent analyses.

We used volumetric water contents and temperature as soil variables. We measured soil water content (\%) at four locations within each plot every month from February to October in all three years by using a Hydrosense CS 620 soil moisture measurement system with $20 \mathrm{~cm}$ probe rods. We used a TR 50 datalogger to record the surface soil temperature (at a depth of $5 \mathrm{~mm}$ ) and the temperature at a depth of $20 \mathrm{~cm}$ from April 2004 to December 2006 every hour. Then we calculated annual mean and minimum values of these two characteristics and used as soil variables.

For each year of the experiment, we applied principal components analysis (PCA) to test which of these environmental variables was linked to the diversity of ground beetles. PCA is an effective method with multiple variables. In addition, it helps to remove correlation existing among the variables and produces perfectly orthogonal PC axes. The principal components determined in this way can be then analyzed for the links with the major variables as well as with the dependent variables (see below for the description of multiple regression analysis). The PCA was performed with PC-ORD ver. 4 (McCune and Mefford 1999).

\section{Biodiversity assessment}

\section{Vegetation regeneration}

We assessed the effects of experimental manipulations on plant diversity by analysis of vegetation regeneration. We measured coverage and Simpson's diversity of newly recruited plants after clearing ground vegetation, tree cutting and litter removal using as described above (see the previous sub-section). The effects of experimental manipulations on the coverage and diversity of regenerating vegetation were analyzed using repeated measures ANOVA. Replication units (subject factor) were three years of the study and within-subject factors were manipulations types 


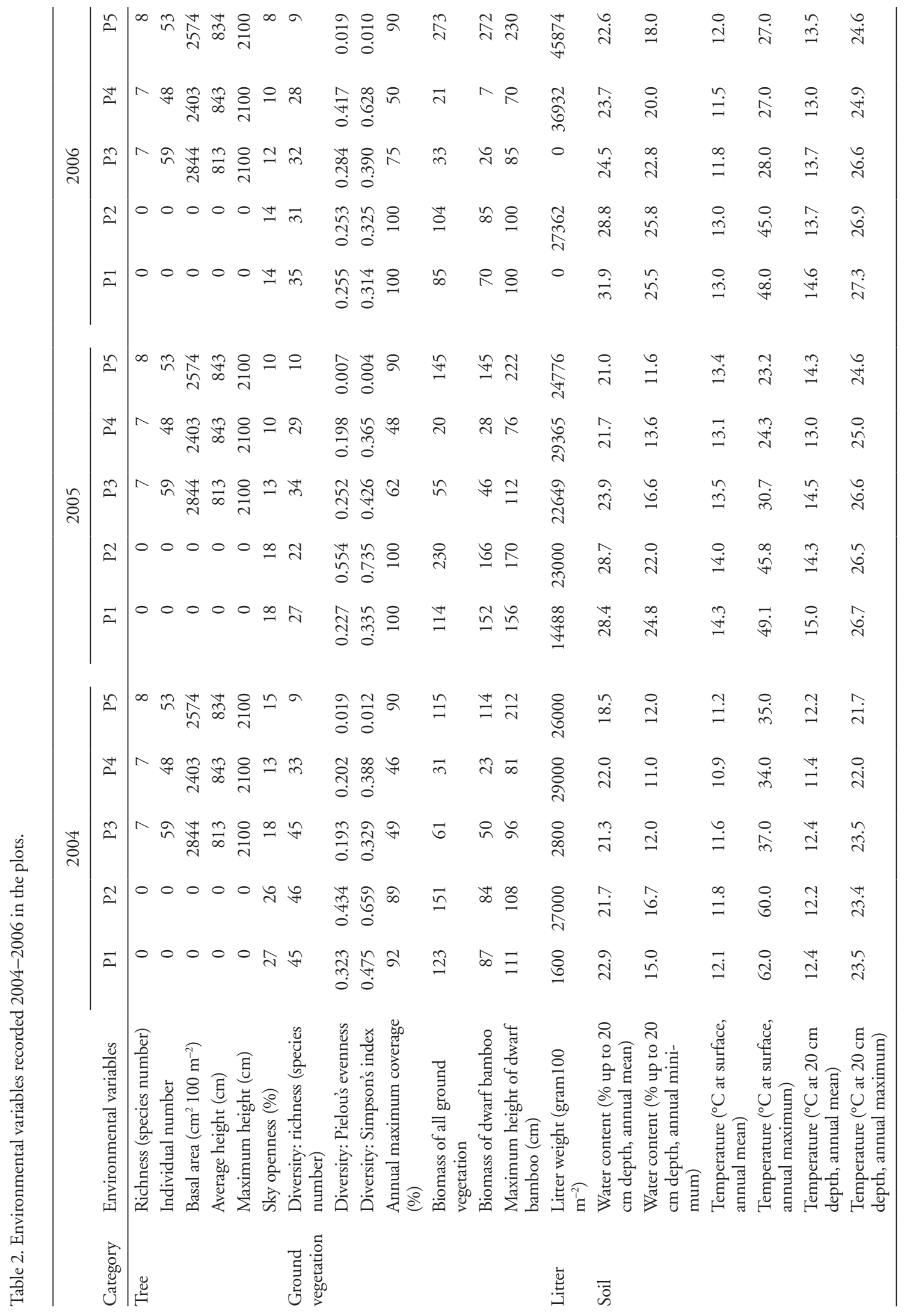




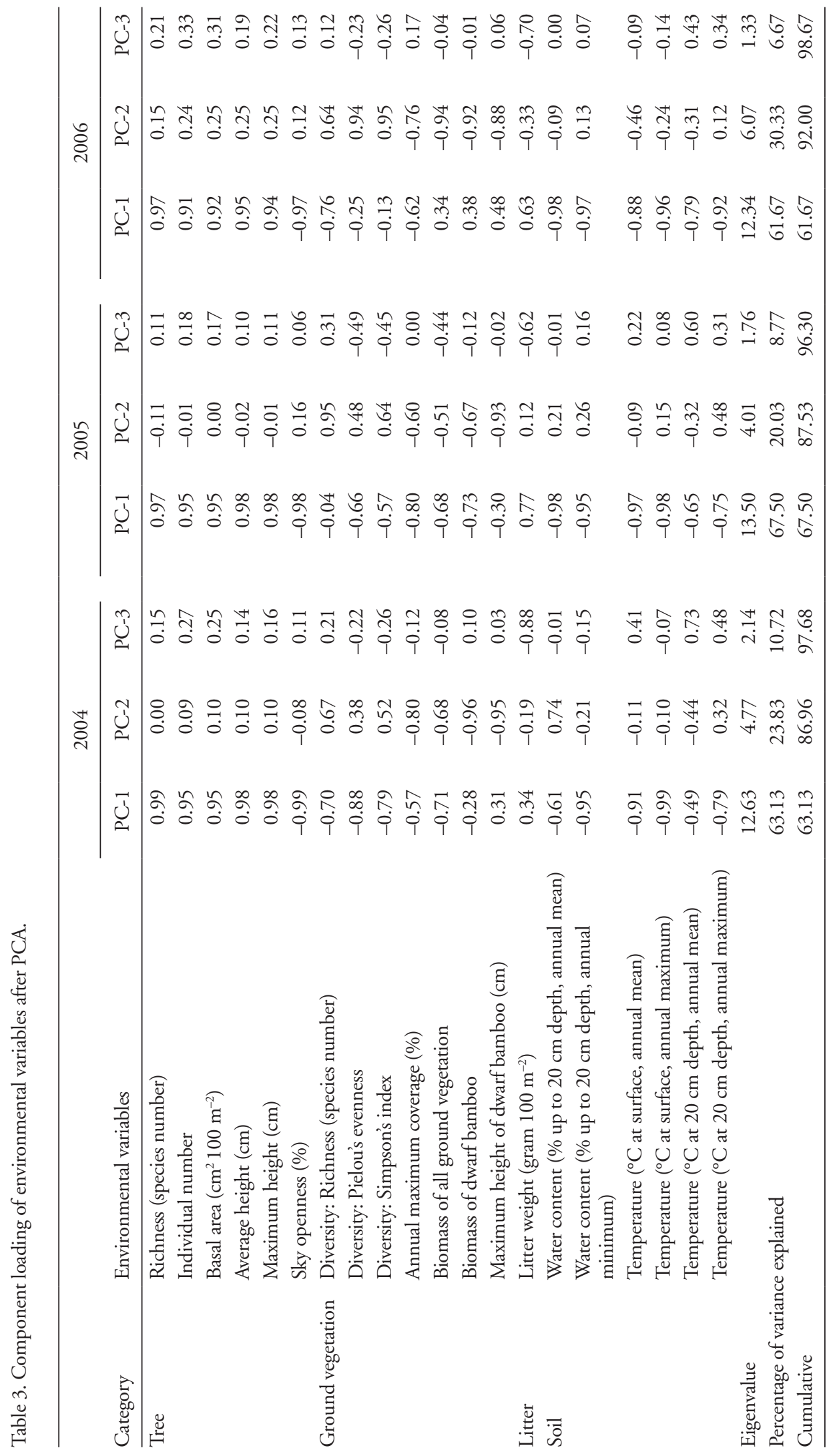


(tree cutting, litter removal and ground vegetation clearing).

\section{Ground beetle community}

We used pitfall traps (plastic cups: $6.5 \mathrm{~cm}$ top diameter $\times$ $7.5 \mathrm{~cm}$ depth) to sample the ground beetle community. We buried 14 traps separated by $2 \mathrm{~m}$ at the center of each plot (the minimum distance between sampling sites of the different plots was $8 \mathrm{~m}$ ). Traps were installed once a month from April to December 2004, in June and October 2005 and from May to November 2006. We left the traps in place for five consecutive days, and then brought them back to our laboratory to count and identify all trapped animals. We analyzed the Carabidae beetles plus Eusilpha japonica excluding their larval stage. We assessed the abundance of each species by the number of individuals, and used these data for the analyses of the ground beetle community structure.

We described alpha-diversity of ground beetles (diversity within the plots) using Simpson's diversity index (above). We analyzed the effects of experimental manipulations on ground beetle abundance (number of caught individuals per sampling) and Simpson's diversity using repeated-measures ANOVA (above).

We analyzed the links between ground beetle Simpson's diversity and the environmental variables using multiple linear regression with the forward stepwise procedure $\left(\mathrm{p}_{\text {in }}\right.$ $\leq 0.05$ to add, $\mathrm{p}_{\text {out }} \geq 0.05$ to remove). The PCA scores obtained previously from the analysis of the 20 environmental variables (above) were used as the independent variables, and Simpson's index of diversity for the ground beetles was used as the dependent variable.

We described the beta-diversity patterns of ground beetles (diversity between the plots) based on the cluster analysis. We used the relative (quantitative) Sorensen distance and calculated group averages (McCune and Mefford 1999). In this analysis, we $\log _{2}$-transformed the numbers of beetles.

\section{Results}

\section{Environmental variable analyses}

The values of all environmental variables measured in experimental plots for the three years of study are shown on Table 2. The subsequent PCA found that the first three principal components (PCs) explained more than $95 \%$ of the variations in the original variables and showed consistently similar trends in all three years (Table 3). PC1 was strongly correlated with tree variables and with most soil variables; high $\mathrm{PC} 1$ scores coincided with high diversity and abundance of tree species, closed canopy, and cool and dry soil conditions. PC2 was most strongly correlated with the ground vegetation variables: high score of PC2 generally coincided with high species diversity and but low abundance of the ground vegetation. PC3 was most strongly correlated with litter dry weight.

The experimental cutting of trees in March 2004 decreased the total basal area in P1 and P2 plots to zero in contrast with the relatively high BA (ca $\left.2500 \mathrm{~cm}^{2} 100 \mathrm{~m}^{-2}\right)$ in the tree-uncut plots (P3, P4, and P5). Consequently, the canopy openness in the tree-cut plots increased noticeably compared to the tree-uncut plots ( $\geq 26 \%$ vs $\leq 18 \%$ ).

Removal of litter from the plots P1 and P2 in March of 2004 and 2006 caused noticeable differences between these and other plots at the beginning, but this after-manipulation difference in litter weight decreased gradually and almost disappeared in September of the corresponding year (Fig. 1A).

Measurements of soil water contents at $20 \mathrm{~cm}$ depth showed that water contents in the soil of tree-uncut plots (P3, P4 and P5) was less than that in the tree-cut plots from July 2004 onwards during all three years of study (Fig. 1B). Most likely, trees evaporated more water through transpiration than the regenerating vegetation.

Tree cutting increased maximum surface temperature compared to tree-uncut plots during all three years (maxima $45-62^{\circ} \mathrm{C}$ versus $27-37^{\circ} \mathrm{C}$ ). However, the temperature at the depth of $20 \mathrm{~cm}$ was practically indistinguishable (maxima $23-27^{\circ} \mathrm{C}$ versus $22-27^{\circ} \mathrm{C}$ ).

A

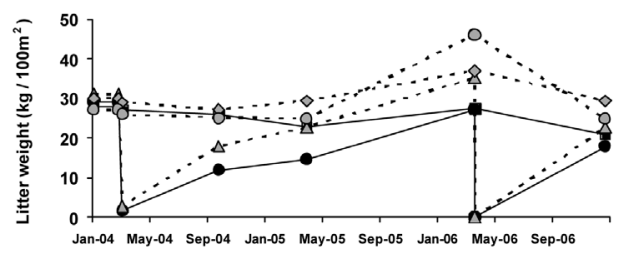

B

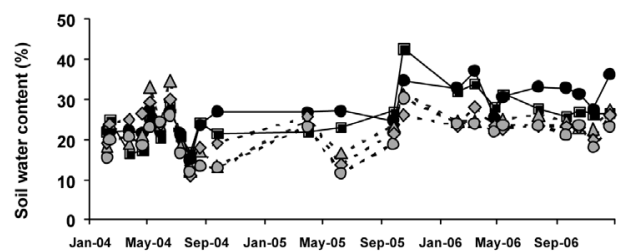

c

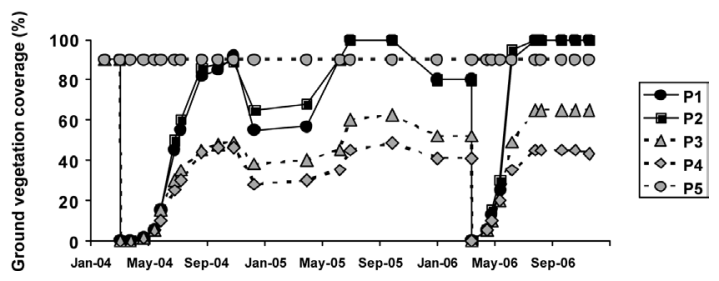

Fig. 1. Environmental changes after vegetation manipulations from 2004 to 2006. (A) litter dry weight, (B) soil water content, (C) ground vegetation cover. 


\section{Biodiversity assessment}

\section{Effects on vegetation regeneration}

The effects of tree cutting on the regeneration of vegetation were obvious (Fig. 1C) as the coverage of vegetation regenerated more rapidly in the tree-cut plots (P1 and P2) than in the tree-uncut plots (P3 and $\mathrm{P} 4)$.

Clearing ground vegetation prompted rapid regeneration of vegetation cover (Fig. 2A), with many new species recruited as shown by the sharply increased Simpson's diversity index jumped up more than 50 times, but tree cutting did not have a significant effect on the diversity of regenerating vegetation (Fig. 2B). At the same time, tree cutting considerably modified the rate of vegetation regeneration, as the plant coverage grew significantly more rapidly in the absence of trees than in their presence (Fig. $2 A)$. Litter removal did not have a noticeable effect on regeneration rate or diversity (Fig. 2A, B).

\section{Effects on ground beetle community}

The share of ground beetles was 51-64\% of all animals trapped in the pitfalls during the study period. Litter removal strongly decreased the abundance of ground beetles per sampling, but tree cutting and ground vegetation clearing produced weak and insignificant effects on ground beetle abundance (Fig. 3A). At the same time, tree cutting significantly increased the diversity of ground beetles within the plots (alpha diversity), whilst ground vegetation clearing or litter removal did not produce noticeable effects on the alpha diversity (Fig. 3B).

Multiple regression analysis revealed a link between the PC1 axis obtained from the analysis of 20 environmental variables and ground beetle diversity: the regression between the values of Simpson's diversity index and PC1 was significant in $2004(\mathrm{Y}=0.68-0.023 \times \mathrm{X}, \mathrm{p}=0.04, \mathrm{~F}=$ $\left.12.43, \mathrm{R}^{2}=0.81\right)$, not so in $2005(\mathrm{Y}=0.61-0.022 \times$ $\mathrm{X}, \mathrm{p}=0.14, \mathrm{~F}=3.84, \mathrm{R}^{2}=0.42$ ), but significant again in $2006\left(\mathrm{Y}=0.53-0.048 \times \mathrm{X}, \mathrm{p}=0.05, \mathrm{~F}=9.92, \mathrm{R}^{2}=\right.$ $0.77)(\mathrm{Y}=$ Simpson's diversity index, $\mathrm{X}=\mathrm{PC} 1)$. As $\mathrm{PC} 1$ axis was highly correlated with tree variables (Table 3 ), this result may also point to the importance of tree cutting for ground beetle diversity.

Cluster analysis revealed considerable beta-diversity of ground beetles among plots (Fig. 4). Generally, species composition of ground beetle communities in the tree-cut plots were dissimilar to those in tree-uncut plots, although clustering pattern was not consistent through the three years of our study, probably due to ongoing successional processes.

\section{Discussion}

Our study shows that small-scale disturbance of vegetation had a strong effect on the regeneration of vegetation as well as on ground beetle community. The increase in the diver-
A

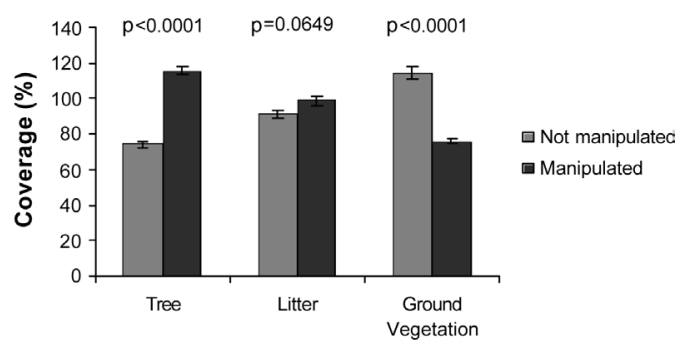

B

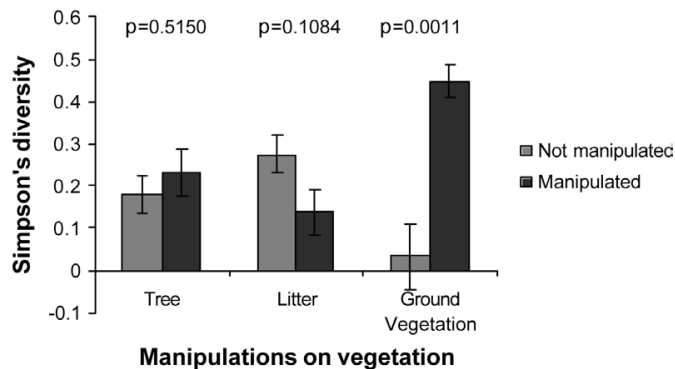

Fig. 2. The effects of disturbance type on regeneration of vegetation in experimental plots. (A) coverage, (B) Simpson's diversity, $\mathrm{p}$-values are calculated using repeated-measures ANOVA. The error bars show \pm 1 SE.
A

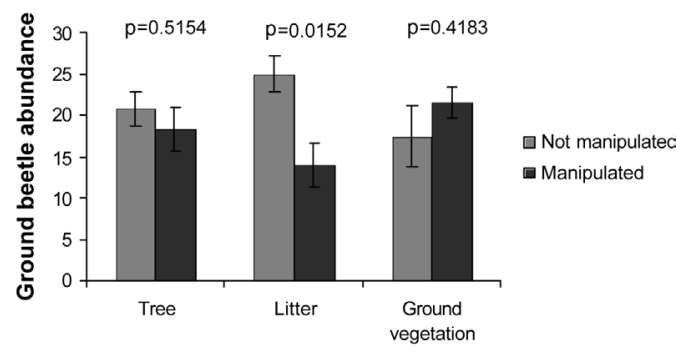

B

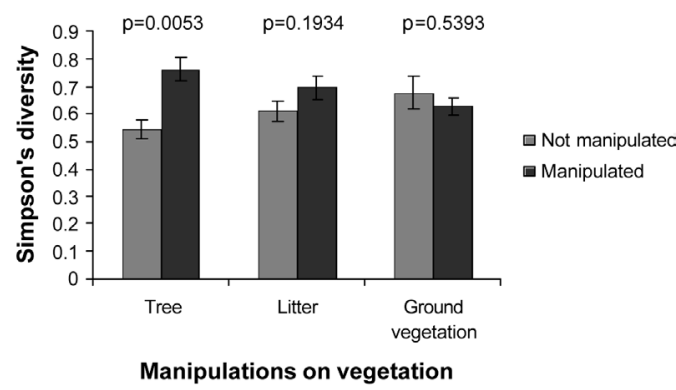

Fig. 3. The effects of disturbance type on ground beetle diversity in experimental plots, p-values are calculated using repeatedmeasures ANOVA. The error bars show $\pm 1 \mathrm{SE}$. 


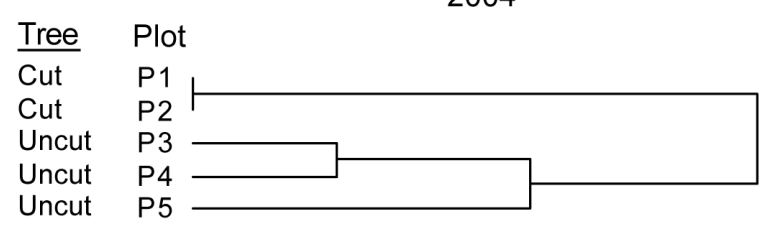

2005

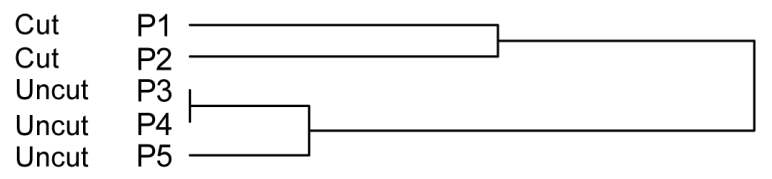

2006

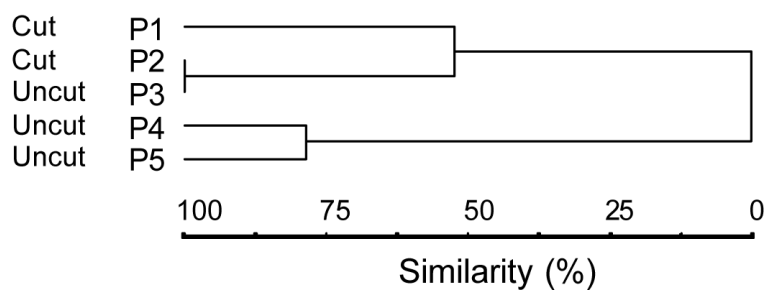

Fig. 4. Cluster analysis of the ground beetle assemblages in experimental plots performed separately for each year of the experimental study (2004, 2005 and 2006). Taxonomic similarity is measured by Sorensen's relative (quantitative) distance.

sity through recruitment of new species after ground vegetation clearing was dramatic. Tree cutting was important for the rate of regeneration but not so for the recruitment of new species. We may conclude that clearing of ground vegetation may be effective in opening a regeneration niche for many plant species even under tree canopy. However, tree cutting was important for ground beetle diversity as shown both by ANOVA and regression analyses. Tree cutting increased the ground beetle diversity not only at alpha scale (higher diversity within plots), but also at beta scale (significant taxonomic distance found by cluster analysis). Butterfield et al. (1995) also found that clear felling was a key factor in increasing species richness of carabid beetles in coniferous forests. It should be noted that these authors based their study on large-scale vegetation disturbances, while our study demonstrates that small-scale vegetation disturbances also can improve ground beetle diversity. We also found a significant effect of litter removal on the abundance of ground beetles. This effect partly could be caused by strong responses of the most abundant species, E. japonica, to litter removal (Shibuya et al. 2008).

The analysis of as many as 20 environmental variables indicated that tree cutting produced multiple effects and could influence ground beetle diversity not only directly, but also indirectly. For example, vegetation recovered at least two times more rapidly when freed from the competition with trees, and hence could support more ground beetles. Growing vegetation may offer not only the shelter to escape vertebrate predators, but also may serve as a food source. In fact, we observed that the abundance of other invertebrates such as Lepidoptera and Diptera increased in plots with rapidly regenerating vegetation compared to the plots where regeneration was slow due to presence of trees (Shibuya pers. obs.).

Based on independent analytical approaches, our study shows that tree cutting may be an important component of a sound conservation practice in combination with ground vegetation clearing and litter removal. Tree cutting even at small-scale has pronounced effects on forest environment overall, and particularly increased the diversity of ground beetles, which are popular bioindicators of environmental changes in forests. Our results suggest that even if full-scale coppicing is not feasible any more for economical reasons, conservation of abandoned forests may be based on lowintensity labor including tree cutting on restricted areas. Finally, ground beetles appeared to be surprisingly sensitive to small vegetation disturbances and thus can be suggested for monitoring such small-scale disturbance-based conservation practices.

Our experimental design lacked spatial replication dictated by the need of limiting manipulations on vegetation to small areas. Therefore, certain caution is required when interpreting our results. However, lack of spatial replication was compensated by repeated measures approach. The effects that were consistently repeating during the three years of study we considered robust and significant.

Acknowledgements - We thank Z. Kikvidze for reviewing the manuscript and assisting in statistical analyses, T. Kagaya for suggestions on the multivariate analyses, U. Jinbo, H. Yamashita, K. Sasakawa and H. Ikeda for supplying us with references, and M. Hori for the helpful advice and his encouragement to proceed this study, as well as the staff of Musashi-Kyûryô National Park for their cooperation.

\section{References}

Brown, R. D. and Yokohari, M. 2003. Ideological contribution of Satoyamas. - In: Takeuchi, K. et al. (eds), Satoyama: the traditional rural landscape of Japan. Springer, pp. 1-7.

Butterfield, J. et al. 1995. Carabid beetle communities as indicators of conservation potential in upland forests. - For. Ecol. Manag. 79: 63-77.

Fukamachi, K. et al. 2001. The change of a Satoyama landscape and its causality in Kamiseya, Kyoto prefecture, Japan between 1970 and 1995. - Landscape Ecol. 16: 703-717.

Hiroki, S. 2002. Satoyama no seitaigaku (Satoyama ecology). Nagoya Univ. Press.

Ichinose, T. and Katoh, K. 1998. Factors influencing bird distribution among isolated woodlots on a heterogeneous land- 
scape in Saitama pref., Japan. - Ekologia (Bratislava) 17: 298-310.

Iida, S. and Nakashizuka, T. 1995. Forest fragmentation and its effect on species diversity in sub-urban coppice forests in Japan. - For. Ecol. Manag. 73: 197-210.

Ikeda, H. et al. 2007. Flight capabilities and feeding habits of silphine beetles: are flightless species really 'carrion beetles'? Ecol. Res. 22: 237-241.

Inoue, T. 2003. Chronosequential change in a butterfly community after clear-cutting of deciduous forests in a cool temperate region of central Japan. - Entomol. Sci. 6: 151-163.

Irmler, U. 2003. The spatial and temporal pattern of carabid beetles on arable fields in northern Germany (Schleswig-Holstein) and their value as ecological indicators. - Agr. Ecosyst. Environ. 98: 141-151.

Ishii, M. 2005. Seitaigaku kara mita Satoyama no shizen to hogo (Nature and conservation of Satoyama from the ecological perspective). - Kodansha Sci. Press.

Ishitani, M. 1996. Ecological studies on ground beetles (Coleoptera: Carabidae, Brachinidae) as environmental indicators. - Miscell. Rep. of the Hiwa Mus. for Nat. Hist. 34: 1-110, in Japanese with English summary.

Ishitani, M. et al. 2003. Changes in carabid beetle assemblages across an urban-rural gradient in Japan. - Ecography 26: 481-489.

Magurran, A. E. 1988. Ecological diversity and its measurement. - Croom Helm.

McCune, B. and Mefford, M. J. 1999. PC-ORD: multivariate analysis of ecological data, ver. 4. MjM Software Design.

Moriyama, H. 1988. Shizen wo mamoru toha douiu koto ka. Nouson Gyoson Bunka Kyoukai, Tokyo, in Japanese.

Niemelä, J. et al. 1993. Effects of clear-cut harvesting on boreal ground-beetle assemblages (Coleoptera: Carabidae) in western Canada. - Conserv. Biol. 7: 551-561.

Niemelä, J. et al. 2007. The effects of forestry on carabid beetles (Coleoptera: Carabidae) in boreal forests. - J. Insect Conserv. 11: 5-18.

Nishinaka, Y. and Ishii, M. 2007. Mosaic of various seral stage of vegetation in the Satoyama, the traditional rural landscape of Japan as an important habitat for butterflies. - Trans. Lepid. Soc. Japan 58: 69-90.
Ohwaki, A. et al. 2007. Butterfly assemblages in a traditional agricultural landscape: importance of secondary forests for conserving diversity, life history specialists and endemics. Biodiv. Conserv. 16: 1521-1539.

Okubo, S. et al. 2005. Management and micro-scale landform determine the ground flora of secondary woodlands and their verges in the Tama Hills of Tokyo, Japan. - Biodiv. Conserv. 14: 2137-2157.

Pielou, E. C. 1975. Ecological diversity. - Wiley.

Rainio, J. and Niemelä, J. 2003. Ground beetles (Coleoptera: Carabidae) as bioindicators. - Biodiv. Conserv. 12: 487506.

Scott, W. A. and Anderson, R. 2003. Temporal and spatial variation in carabid assemblages from the United Kindom environmental change network. - Biol. Conserv. 110: 197210.

Shibuya, S. et al. 2008. Differential sensitivity of ground beetles Eusilpha japonica and Carabidae to vegetation disturbance in an abandoned coppice forest in central Japan. - Eurasian J. For. Res. 11: 61-72.

Shimada, M. 1985. Studies on inhabitant of insects in parks and open spaces in the urban area. - Japan. Inst. Landscape Architect. 48: 187-192, in Japanese with English summary.

Shimada, M. et al. 1991. Studies on inhabitant environment of insects in parks and open spaces in urban area. - Japan. Inst. Landscape Architect 54: 287-292, in Japanese with English summary.

Takenaka, A. 2007. CanopOn 2.02, <http://takenaka-akio.cool. ne.jp/etc/canopon $2 />$.

Takeuchi, K. 2003. Satoyama landscapes as managed nature. In: Takeuchi, K. et al. (eds), Satoyama: the traditional rural landscape of Japan. Springer, pp. 9-16.

Taniwaki, T. et al. 2005. Comparison of ground beetle fauna on managed and short and long-term unmanaged floors in a suburban forest. - J. Japan. Soc. Reveget. Tech. 31: 260 268, in Japanese with English summary.

Thiele, H. U. 1977. Carabid beetles in their environments. A study on habitat selection by adaptations in physiology and behavior. - Springer. 